\title{
VALIDATED RP-HPLC METHOD AND UNIQUE MOBILE PHASE FOR THE SIMULTANEOUS ESTIMATION OF AMLODIPINE BESYLATE AND VALSARTAN FROM SOLID DOSAGE FORM AND ROSUVASTATIN AND VALSARTAN FROM BULK
}

\author{
DYADE GK ${ }^{1 *}$, SAWANT RL ${ }^{2}$ \\ ${ }^{1}$ Department of Pharm Chem, SVPM'S College of Pharmacy, Malegaon (BKII), Baramati - 413 115, Maharashtra, India. ${ }^{2}$ Department of Pharm \\ Chem and P. G. Studies, Dr. VVPF'S College of Pharmacy, Vilad, Ahmadnagar, Savitribai Phule Pune University, Pune, Maharashtra, India
}

Received: 01 February 2019, Revised and Accepted: 25 February 2019

ABSTRACT

Objective: A reverse-phase high-performance liquid chromatographic (RP-HPLC) method was developed and validated for the simultaneous estimation of amlodipine besylate (AD) and valsartan (VAL) in pharmaceutical dosage form, and rosuvastatin (RV) and VAL from the bulk mixture.

Method: Chromatographic separation was performed on RP-C $\mathrm{C}_{18}$ column. The optimized unique mobile phase (acetonitrile:water and pH adjusted to 4.8 with acetic acid) was pumped at a flow rate of $0.8 \mathrm{ml} / \mathrm{min}$ in the ratio of $75: 25 \% \mathrm{v} / \mathrm{v}$, and the eluents were monitored at $245 \mathrm{~nm}$.

Results: The assay was performed with tablet and percentage of assay was found to 101.39 for AD and 100.05 for VAL, respectively, and with bulk mixture, percentage of assay was found to 99.58 for RV and 100.32 for VAL, respectively. Linearity was obtained in the concentration range of $1-12 \mu \mathrm{g} / \mathrm{ml}$ for AD, $5-50 \mu \mathrm{g} / \mathrm{mL}$ for VAL, and $2-20 \mu \mathrm{g} / \mathrm{ml}$ for RV. The method was statistically validated and RSD was found to be $<2 \%$, indicating high degree of accuracy and precision of the proposed RP-HPLC method.

Conclusions: The method suggests usefulness of unique mobile phase during the estimation of two or more multicomponent dosage forms. Due to its simplicity, rapidness, high precision, and accuracy, the proposed RP-HPLC method can be applied for simultaneous determination of AD and VAL in pharmaceutical dosage form, and RV and VAL in bulk mixture.

Keywords: Amlodipine besylate, Valsartan, Rosuvastatin, Reverse-phase high-performance liquid chromatographic, Chromatograph.

(C) 2019 The Authors. Published by Innovare Academic Sciences Pvt Ltd. This is an open access article under the CC BY license (http://creativecommons. org/licenses/by/4. 0/) DOI: http://dx.doi.org/10.22159/ajpcr.2019.v12i4.31878

\section{INTRODUCTION}

Amlodipine besylate (AD), 2 - [(2-amino ethyl)-methyl]-4-(2 - chloro phenyl)-1, 4-dihydro-6 -methyl-3, 5-pyridine dicarboxylic acid 3-ethyl5 -methyl ester, benzene sulfonate, is a potent dihydrocalcium channel blocker [1-5]. Various analytical methods have been reported for the assay of $\mathrm{AD}$ alone or in combination with other antihypertensive agents in pharmaceutical formulations. These include reverse-phase high-performance liquid chromatography [6-8], stability-indicating LC method [9], HPLC method [10,11], in plasma [12,13], high-performance thin-layer chromatography (HPTLC) [14], HPTLC in plasma [15], and Ultra-performance liquid chromatography (UPLC) [16] and ultraviolet (UV) spectroscopic methods [17-22].

Valsartan (VAL) chemically, N-(1-oxopentyl)-N-[(2'-(1H-tetrazol-5yl) (1, 1'-biphenyl)-4-yl) methyl]-L-valine, is a potent angiotensin receptor blocker [1-3]. Methods such as HPLC [23-26], in plasma [27], bioanalytical method [28], UPLC method [29], and thermogravimetric method [30] are reported for estimation of VAL alone or in combination with other drugs.

Rosuvastatin (RV) chemically, 7-[4-(4-fluorophenyl)-6-(1-methylethyl)-2-(methyl-methylsulfonyl-amino)-pyrimidin-5-yl] 3, 5-dihydroxy-hept-6-enoic acid, is one of the more recently introduced statins. Statins are 3-hydroxy-3-methylglutaryl (HMG)-CoA reductase inhibitors. The conversion of HMG-CoA to mevalonic acid is especially important because it is a primary control site for cholesterol biosynthesis [1-3]. Methods such as RP-HPLC [31-33], simultaneous UV spectrophotometric methods [34,35], in plasma [36], and degradation study [37] are reported for estimation of RV alone or in combination with other drugs.
The drugs are official in BP [38]. AD, VAL, and RV are official in IP [39]. The chemical structures of AMB, VAL, and RV are shown in Fig. 1.

Literature survey revealed that several methods are reported for the estimation of AD, VAL, and RV individually as well as AD with VAL and along with other antihypertensive drugs. However, the combined determination of RV and VAL remains to be investigated. The method is found suitable for simultaneous determination of these bicomponents with single mobile phase. Ability of unique mobile phase for the estimation of two or more formulations is advantageous during analysis which saves time as well as provides stable chromatographic conditions. Therefore, an attempt has been made to develop a suitable analytical method for simultaneous estimation of AM and VAL from their pharmaceutical formulations and RV and VAL in bulk mixture. RP-HPLC methods have been widely used for routine quality control assessment of drugs due to their accuracy, repeatability, selectively, sensitivity, and specificity. We have developed a simple, precise, accurate, and specific RP-HPLC method for the simultaneous determination of AM and VAL, and RV and VAL with unique mobile phase. Analytical method must be validated before use to ensure that the method under consideration is capable of giving reproducible and reliable results. The proposed HPLC with UV detection method was validated in accordance with the International Conference on Harmonization (ICH) guidelines [40,41], by assessing its selectivity, linearity, accuracy, precision, limit of detection (LOD), and limit of quantitation (LOQ).

\section{METHODS}

\section{Instrumentation}

Analysis was performed with a Shimadzu (Japan) prominence chromatograph equipped with an LC-20 AT solvent delivery system, a universal loop injector (Rheodyne 7725) of injection capacity of $20 \mu \mathrm{l}$, 


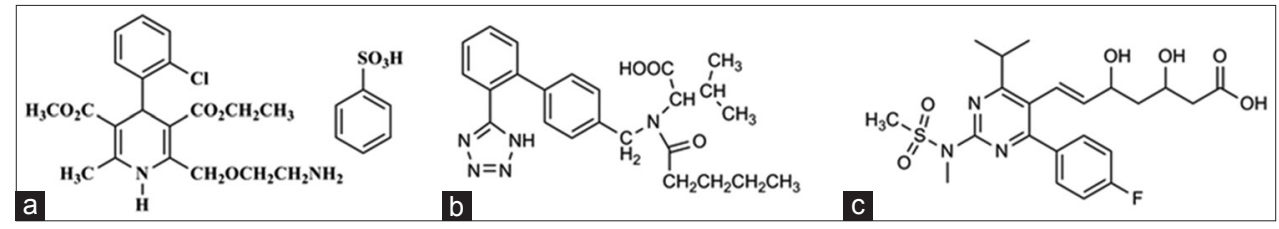

Fig. 1 Chemical structure of (a) amlodipine besylate, (b) valsartan, (c) rosuvastatin

and an SPD-20A UV-Visible detector set at $245 \mathrm{~nm}$. The equipment was controlled by a PC workstation with clarity software. Compounds were separated on a Phenomenex Luna $\mathrm{C}_{18}$ column $(250 \mathrm{~mm} \times 4.6 \mathrm{~mm}$ i.d., 5- $\mu \mathrm{m}$ particle size) under reversed-phase partition conditions. The mobile phase was a 75:25 \% (v/v) mixture of acetonitrile:water (pH $4.8 \pm 0.2$, adjusted with acetic acid). The flow rate was $0.8 \mathrm{ml} / \mathrm{min}$ and the run time was $8 \mathrm{~min}$. Before analysis, both the mobile phase and sample solutions were degassed by the use of a sonicator (Labman Scientific Instruments, Chennai) and filtered through a $0.2 \mu \mathrm{m}$ filter (Pall Corporation, Mumbai). The identity of the compounds was established by comparing the retention times of compounds in the sample solution and standard solutions. Chromatography was performed in an ambient temperature maintained at $40 \pm 1^{\circ} \mathrm{C}$. The UV spectrum of $\mathrm{AD}, \mathrm{RV}$, and VAL for selecting the working wavelength of detection was taken using a Shimadzu-1700 Double-beam UV-Visible Spectrophotometer (Shimadzu, Kyoto, Japan).

\section{Reagents and chemicals}

Pharmaceutically, pure samples of AD and RV from Cure Pharma, Pune, and VAL from FDC, Mumbai, were obtained as a gift samples and the commercial formulation Amlopres VL tablets: AD - $10 \mathrm{mg}$ and VAL $160 \mathrm{mg}$ were procured from local market. HPLC-grade acetonitrile, water, and acetic acid (HPLC grade) were obtained from Qualigens India Pvt., Ltd., Mumbai, India.

\section{Preparation of stock solution of AD, RV, and VAL}

About $10 \mathrm{mg}$ of $\mathrm{AD}, 20 \mathrm{mg}$ of $\mathrm{VAL}$, and $10 \mathrm{mg}$ of RV were accurately weighed and transferred into $50 \mathrm{ml}$ volumetric flasks separately. It was dissolved in mobile phase and the volume was made up to $50 \mathrm{ml}$ with mobile phase. From this standard stock solution, the aliquots of solution were further diluted with mobile phase to obtain standard solution with conc. range of $1-12 \mu \mathrm{g} / \mathrm{ml}$ for $\mathrm{AD}, 5-50 \mu \mathrm{g} / \mathrm{ml}$ for VAL, and 2-20 $\mu \mathrm{g}$ for RV. Furthermore, mixed standard solution was prepared simulated to marketed pharmaceutical dosage form.

\section{Plot of calibration curve}

Calibration curve for each drug was plotted at the concentrations of $1-12 \mu \mathrm{g} / \mathrm{ml}$ for AD, $2-20 \mu \mathrm{g} / \mathrm{ml}$ for RV, and $5-50 \mu \mathrm{g} / \mathrm{ml}$ for VAL. All the standard solutions were filtered through syringe filter and injected $20 \mu \mathrm{l}$ solutions each time with Hamilton syringe. The chromatograph was read and the peak areas were measured. Peak areas were then plotted against their respective concentrations for AD, RV, and VAL. From the calibration curve, it was found that all the drugs were linear in the concentration range of 1-12 $\mu \mathrm{g} / \mathrm{ml}, 2-20 \mu \mathrm{g} / \mathrm{ml}$, and 5-50 $\mu \mathrm{g} / \mathrm{ml}$ for $\mathrm{AD}, \mathrm{RV}$, and VAL, respectively. The calibration graph was used as a reference to know quantitatively conc. of unknown solution of dosage form.

Statistical parameters - standard regression curve analysis was obtained by the use of Microsoft Office Excel software and means, standard deviations, and coefficient of variance were calculated.

\section{Assay of tablet formulation and bulk mixture}

The 20 tablets of the formulation of AD and VAL were weighed and average weight of each tablet was found. Tablets of formulation were triturated into a fine powder form with a glass mortar pestle. Tablet powder equivalent to $2.5 \mathrm{mg} \mathrm{AD}$ and $40 \mathrm{mg}$ of VAL was quantitatively transferred into a $50 \mathrm{ml}$ volumetric flask and dissolved in mobile phase and volume was made up to $50 \mathrm{ml}$ with mobile phase. The solution was sonicated for $15 \mathrm{~min}$, to ensure the uniform and homogenous solution of the drug. Further, solution was centrifuged at $500 \mathrm{rpm}$ for $10 \mathrm{~min}$ and the clear supernatant was collected and filtered through membrane syringe filter (pore size $0.45 \mu \mathrm{m}$ ). The aliquots of clear solution were further diluted to $10 \mathrm{ml}$ with mobile phase to obtain $16 \mu \mathrm{g} / \mathrm{ml}$ of VAL and $1 \mu \mathrm{g} / \mathrm{ml}$ of AD. Each sample solution was injected and the peak areas were measured for the determination of AD and VAL in tablet formulation.

Similarly, the bulk mixture, $10 \mathrm{mg}$ of RV and $80 \mathrm{mg}$ of VAL, was prepared, homogenized and powder equivalent to $2.5 \mathrm{mg}$ of RV and $80 \mathrm{mg}$ of VAL was weighed and transferred into a $50 \mathrm{ml}$ volumetric flask and dissolved in mobile phase and volume was made up to $50 \mathrm{ml}$ with mobile phase. The solution was sonicated for $15 \mathrm{~min}$, to ensure the uniform and homogenous solution of the drug. The aliquot of solution was further diluted to $10 \mathrm{ml}$ with mobile phase to obtain $2 \mu \mathrm{g} / \mathrm{ml}$ of RV and $16 \mu \mathrm{g} / \mathrm{ml}$ of VAL. The solution was filtered through syringe filter (pore size $0.45 \mu$ ) and injected $20 \mu \mathrm{l}$ with Hamilton syringe. Peak areas were measured for the determination of RV and VAL in bulk mixture.

\section{Method validation}

The objective of method validation is to demonstrate that the method is suitable for its intended purpose as it is stated in the ICH guidelines. The method was validated for linearity, precision (repeatability and intermediate precision), accuracy, selectivity, and specificity. Accuracy was assessed by measuring recovery at three different levels. Precision assessed by the measurement of intra- and inter-day precision. In the intraday study, the concentrations of all the drugs were calculated 6 times on the same day at different time intervals. In the interday study, the concentrations of the drugs were calculated on 6 different days. Selectivity and specificity of the method were assessed by injecting solutions containing all the drugs; after chromatography, three sharp peaks were obtained for all drugs. LOD and LOQ were measured to evaluate the detection and quantitation limits of the method and to determine whether these were affected by the presence of impurities. They were calculated by the use of the equations LOD $=3.3 \sigma / S$ and LOQ $=10 \sigma / S$, where $\sigma$ is the standard deviation of the response and $S$ is the slope of the calibration plot.

\section{RESULTS AND DISCUSSION}

\section{HPLC method development and optimization}

The multicomponent formulations have gained a lot of importance as there is greater patient acceptability, increased potency, and decreased side effects. AD and VAL are a recent combination in the market used for the treatment of hypertension; RV and VAL are combination of antilipidemic agent and angiotensin receptor blocker, respectively. This work was focused on optimization of the conditions for the simple and rapid as well as low cost-effective analysis including a selection of the proper column or mobile phase to obtain satisfactory results.

Solvent type, solvent strength (volume fraction of organic solvent(s) in the mobile phase and $\mathrm{pH}$ of the solution), detection wavelength, and flow rate were varied to determine the chromatographic conditions giving the best separation. The mobile phase conditions were optimized so there was no interference from solvent and excipients. Other criteria, for example, time required for analysis, appropriate $\mathrm{k}$ range $(1<k<10)$ for eluted peaks, assay sensitivity, solvent noise, and use of the same solvent system for extraction of the drugs from the formulations during drug analysis were also considered. 
To optimize mobile phase, chromatogram of all these drugs were obtained in mobile phase acetonitrile:water in 60:40\% v/v, but all drugs eluted after $9 \mathrm{~min}$. Then, the proportion of acetonitrile was increased to $70 \%$ and the result was elution of two drugs within 6 min and VAL eluted after 8 min found. Furthermore, mobile phase composition was changed to methanol:water in proportion $70: 30 \% \mathrm{v} / \mathrm{v}$, the result was distorted signals that were not well defined. Addition of $0.5 \mathrm{~mL}$ acetic acid for adjustment of the $\mathrm{pH}$ resulted in good separation and symmetrical peaks.

To determine the appropriate wavelength for simultaneous determination of $\mathrm{AD}$ and VAL, RV and VAL solutions of these compounds in mobile phase were scanned in the range of 200-400 nm. From the overlaid UV spectra, suitable wavelength considered for monitoring the drugs was $245 \mathrm{~nm}$. Solutions of each substance in the mobile phase were also injected directly for HPLC analysis and the responses (peak area) were recorded at $245 \mathrm{~nm}$. It was observed that all analytes absorbed well at $245 \mathrm{~nm}$, and at this wavelength, there was no interference from the mobile phase or baseline disturbance, and it was, therefore, concluded that $245 \mathrm{~nm}$ was the most appropriate wavelength for analysis of drugs with suitable sensitivity.

The optimum mobile phase was, therefore, acetonitrile:water $(\mathrm{pH} 4.8 \pm 0.1)$ in the ratio 75:25 (v/v). Under these experimental conditions, sharp peaks were obtained for $\mathrm{AD}, \mathrm{RV}$, and VAL at the

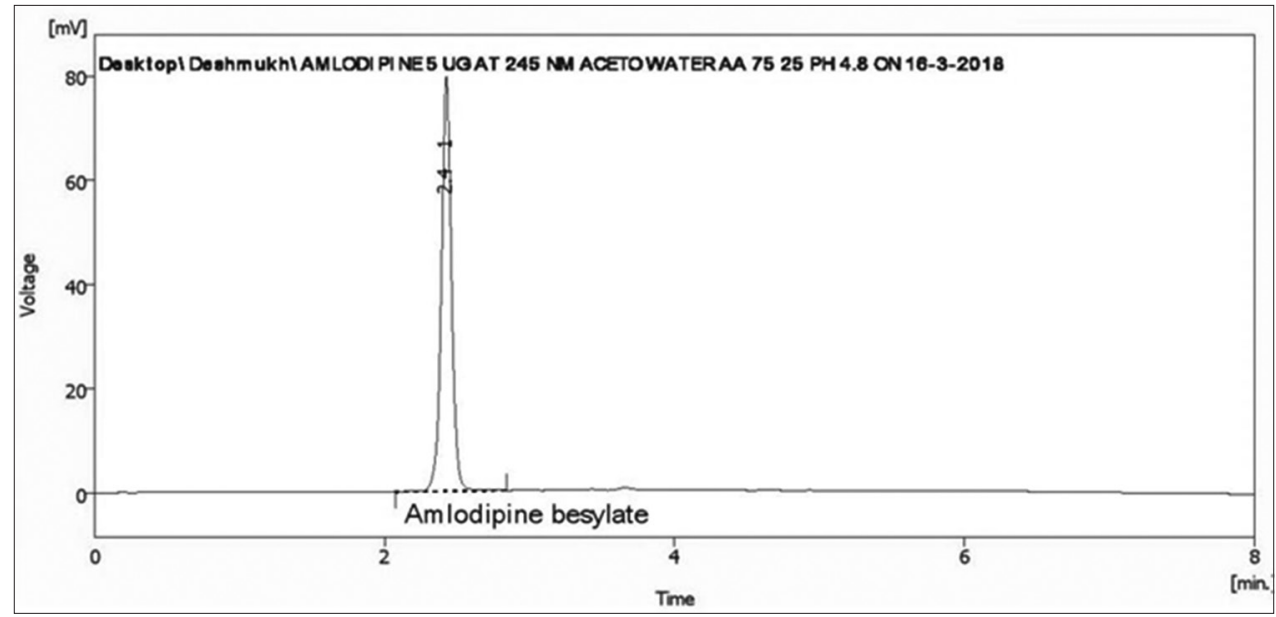

Fig. 2: Optimized chromatogram of amlodipine besylate

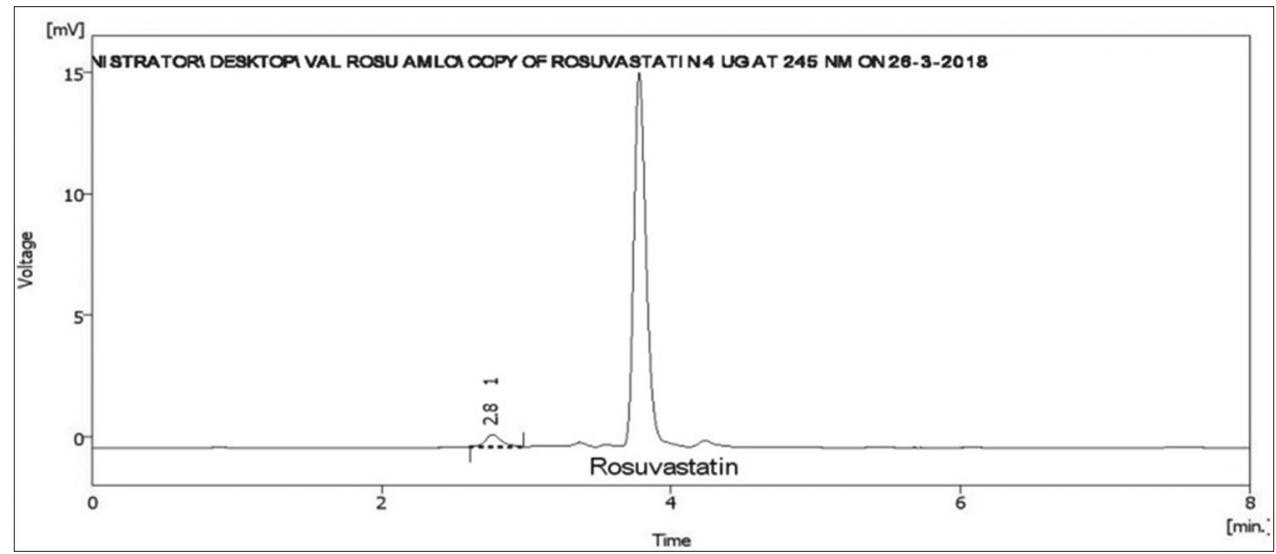

Fig. 3: Optimized chromatogram of rosuvastatin calcium

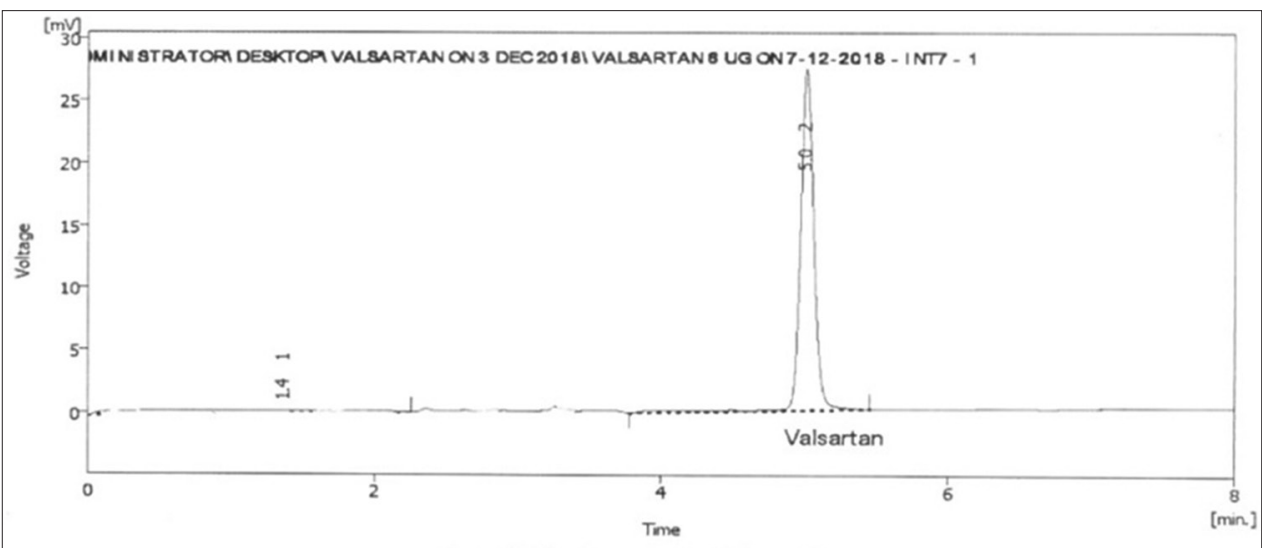

Fig. 4: Optimized chromatogram of valsartan 
Table 1: System suitability study results of AD, VAL, and RV

\begin{tabular}{llll}
\hline Parameters & AD & VAL & RV \\
\hline Retention time* & 2.412 & 5.021 & 4.013 \\
Tailing factor* & 1.173 & 1.121 & 1.257 \\
Asymmetrical factor* & 1.267 & 1.220 & 1.328 \\
Number of theoretical plates & 7344 & 14544 & 9087 \\
Capacity factor* & 2.87 & 4.98 & 5.694 \\
Resolution & 2.398 & 9.323 & 5.694 \\
Flow rate $\mathrm{ml} / \mathrm{min}$ & $0.8 \mathrm{ml} / \mathrm{min}$ & $0.8 \mathrm{ml} / \mathrm{min}$ & $0.8 \mathrm{ml} / \mathrm{min}$ \\
\hline
\end{tabular}

${ }^{*}$ Mean of six determinations. AD: Amlodipine besylate, VAL: Valsartan, RV: Rosuvastatin

Table 2: Linearity data results of AD, VAL, and RV

\begin{tabular}{llll}
\hline Parameters & AD & VAL & RV \\
\hline Detection wavelength & $245 \mathrm{~nm}$ & $245 \mathrm{~nm}$ & $245 \mathrm{~nm}$ \\
Beer's law limit $(\mu \mathrm{g} / \mathrm{ml})$ & $1-12$ & $5-50$ & $2-20$ \\
Correlation coefficient $(\mathrm{r})$ & 0.9998 & 0.99980 & 0.9998 \\
Regression equation & $\mathrm{Y}=37.823 \mathrm{x}+$ & $\mathrm{Y}=22.37 \mathrm{X}+$ & $\mathrm{Y}=45.53 \mathrm{X}+$ \\
(y=mx+c) & 0.744 & 0.575 & 0.2971 \\
Slope $(\mathrm{b})$ & 37.823 & 22.37 & 45.53 \\
Intercept $(\mathrm{a})$ & 0.744 & 0.575 & -0.2971 \\
LOD $(\mu \mathrm{g} / \mathrm{mL})$ & 0.0464 & 0.2077 & 0.1181 \\
LOQ $(\mu \mathrm{g} / \mathrm{mL})$ & 0.1406 & 0.6294 & 0.3579 \\
Z value* & 0.1891 & 0.1434 & 0.0665 \\
\hline
\end{tabular}

*Mean of six determinations. AD: Amlodipine besylate, VAL: Valsartan,

RV: Rosuvastatin

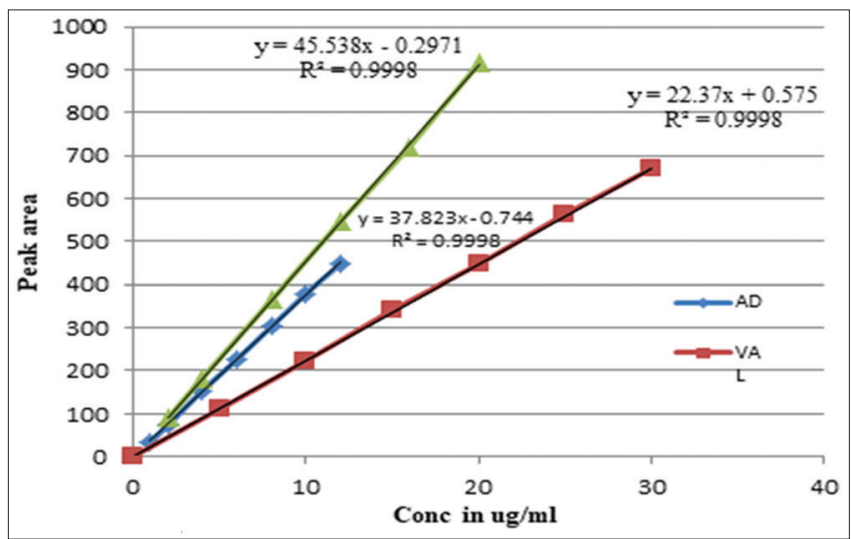

Fig. 5: Calibration curve of amlodipine besylate, rosuvastatin, and valsartan retention times 2.41, 4.01, and 5.02 min, respectively. The optimized chromatogram of $\mathrm{AD}, \mathrm{RV}$, and VAL was obtained and shown in (Figs. 2,3 and 4). The resolution (RS) between AD and VAL was 2.49 and between RV and VAL was found 5.694.

\section{Method validation}

The system suitability parameters such as capacity factor, number of theoretical plates, and tailing factor for all the analytes were found within the limit, indicating the suitability of the system (Table 1$)$. The values obtained for $\mathrm{k}^{\prime}\left(1<\mathrm{k}^{\prime}<10\right)$ and $\mathrm{RS}(>2)$ showed that these chromatographic conditions are appropriate for separation and quantification of all compounds. The number of theoretical plates and the tailing factor was within the acceptance criteria of $>2000$ and $\leq 1.5$, respectively, indicating good column efficiency and optimum mobile phase composition.

\section{Linearity}

Linearity was tested in the concentration range of $1-12 \mu \mathrm{g} / \mathrm{ml}$ for $\mathrm{AD}, 2-20 \mu \mathrm{g} / \mathrm{ml}$ for $\mathrm{RV}$, and $5-50 \mu \mathrm{g} / \mathrm{ml}$ for VAL. The solutions were chromatographed 6 times, in accordance with the International Conference on Harmonization. Separate calibration plots for AD, RV, and VAL were constructed by plotting peak area against the respective concentrations and the method was evaluated by determination of the correlation coefficient and intercept (Fig. 5), calculated in the corresponding statistical study (ANOVA; Z), correlation coefficient $\mathrm{r}^{2}$ values $>0.999$, and intercepts very close to zero confirmed the good linearity of the method. The $\mathrm{Z}$ values calculated for the calibration plots were obtained in satisfactory range, indicating that the variances were not significantly different (Table 2).

\section{Assay}

The percentage label claim of tablet formulation was found to $101.39 \%$ and $100.051 \%$ for $\mathrm{AD}$ and VAL, and $99.58 \%$ and $100.32 \%$ for RV and VAL, respectively. The chromatogram of the analysis of formulation AD and VAL is shown in Fig. 6 and for analysis of bulk mixture RV and VAL is shown in Fig. 7. Precision of the method was confirmed by the repeated analysis of formulation for 6 times. The percentage coefficient of variation (COV) values were found to be 0.6866 and 1.6856 for $\mathrm{AD}$ and VAL, and 0.5894 and 1.1899 for VAL and RV, respectively. The low percentage COV values indicated that all the three drugs showed good agreement with the label claim ensure the precision of the method shown in Table 3.

\section{Precision}

Intraday and interday precision was determined by repeating assay 3 times on the same day for intraday and on 3 different days for interday precision. The intraday precision was studied with standard deviation as 1.5820 and 1.1721 for AD and VAL, and 1.6297 and 1.6067 for RV and VAL, respectively. The interday precision was also studied with standard deviation of 1.7878 and 1.6156 for $\mathrm{AD}$ and VAL, and 1.4446 and 1.2356 for RV and VAL, respectively, tabulated in Table 4.

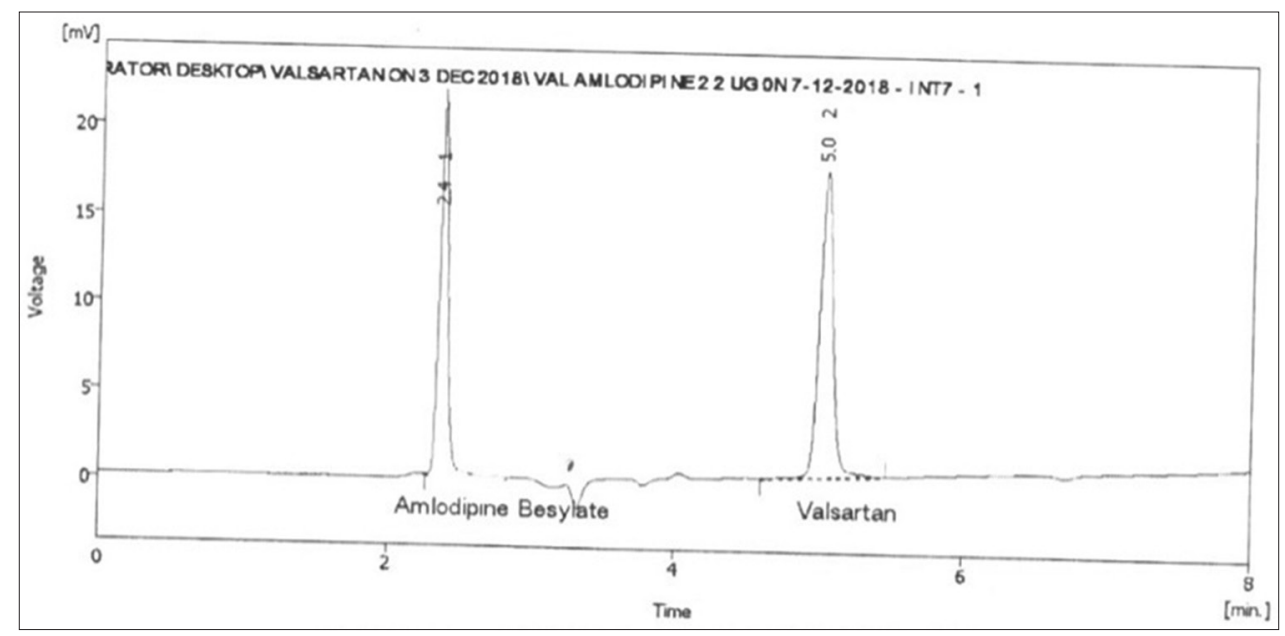

Fig. 6 Chromatogram of amlodipine besylate and valsartan from the formulation 


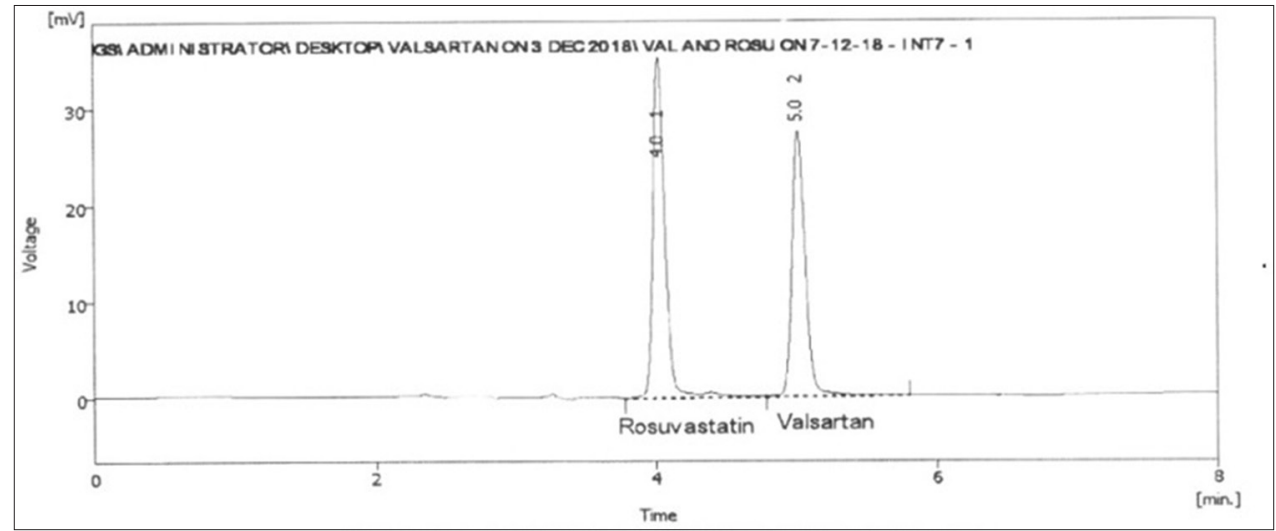

Fig. 7: Chromatogram of rosuvastatin and valsartan from the bulk mixture

Table 3: Results of tablet formulations assay

\begin{tabular}{lllllllr}
\hline Formulation & Drug & $\begin{array}{l}\text { Label claim } \\
\text { (mg/tablet) }\end{array}$ & $\begin{array}{l}\text { Amount found } \\
\text { (mg) n=6 }\end{array}$ & Drug content (\%) & SD & Coeff. of variance (\%) & Std. error \\
\hline Form. of AD and VAL & AD & 10 & 10.1397 & 101.397 & 0.6962 & 0.6866 & 0.28030 \\
& VAL & 160 & 160.083 & 100.051 & 1.6865 & 1.6856 & 0.68853 \\
Bulk mixture of RV and VAL & RV & 10 & 9.9583 & 99.583 & 0.58706 & 0.5894 & 0.23969 \\
& VAL & 80 & 80.2583 & 100.32 & 1.19377 & 1.1899 & 0.48578 \\
\hline
\end{tabular}

Form: Formulation, Std: Standard. SD: Standard deviation, AD: Amlodipine besylate, VAL: Valsartan, RV: Rosuvastatin

Table 4: Results of intraday, interday precision, and recovery analysis of the method

\begin{tabular}{|c|c|c|c|c|c|}
\hline S. No. & Parameter & Level of study & Drug name & S.D. & COV \\
\hline \multirow[t]{9}{*}{1} & \multirow[t]{4}{*}{ Precision of AD and VAL } & \multirow[t]{2}{*}{ Intraday precision } & $\mathrm{AD}$ & 1.5820 & 1.5770 \\
\hline & & & VAL & 1.1721 & 1.1708 \\
\hline & & \multirow[t]{2}{*}{ Interday precision } & $\mathrm{AD}$ & 1.78789 & 1.78110 \\
\hline & & & VAL & 1.61566 & 1.62363 \\
\hline & \multirow[t]{5}{*}{ Recovery study of AD and VAL } & $80 \%$ & \multirow[t]{3}{*}{$\mathrm{AD}$} & 2.71622 & 2.61676 \\
\hline & & $100 \%$ & & 1.2638 & 1.26468 \\
\hline & & $120 \%$ & & 2.0012 & 2.01429 \\
\hline & & $100 \%$ & \multirow{2}{*}{ VAL } & 1.95302 & 1.93829 \\
\hline & & $120 \%$ & & 2.1772 & 2.13954 \\
\hline \multirow[t]{9}{*}{2} & \multirow[t]{4}{*}{ Precision of RV and VAL } & \multirow[t]{2}{*}{ Intraday precision } & RV & 1.6297 & 1.6190 \\
\hline & & & VAL & 1.6067 & 1.5935 \\
\hline & & \multirow[t]{2}{*}{ Interday precision } & RV & 1.4446 & 1.4639 \\
\hline & & & VAL & 1.2356 & 1.2241 \\
\hline & \multirow[t]{5}{*}{ Recovery study of RV and VAL } & $80 \%$ & \multirow[t]{2}{*}{ RV } & 1.8841 & 1.8839 \\
\hline & & $100 \%$ & & 1.4015 & 1.3861 \\
\hline & & $80 \%$ & \multirow[t]{3}{*}{ VAL } & 2.02218 & 2.0087 \\
\hline & & $100 \%$ & & 1.7501 & 1.7236 \\
\hline & & $120 \%$ & & 1.8457 & 1.8188 \\
\hline
\end{tabular}

SD: Standard deviation, COV: Coefficient of variance, AD: Amlodipine besylate, VAL: Valsartan, RV: Rosuvastatin

Accuracy

To check the accuracy of the developed methods and to study the interference of formulation excipients, analytical recovery experiments were carried out as per the ICH guidelines.

The results of the recovery studies and its statistical validation data given in Table 4 indicate high accuracy of the proposed method. The percentage recovery was found to be in the range of 98.73-102.89\% for $\mathrm{AD}$ and $98.58-103.58 \%$ for VAL. The percentage COV values for AD and VAL were found to be 2.0142 and 2.1395 , respectively. The recovery study of RV and VAL was performed and data tabulated in Table 4.

\section{Robustness}

As defined by the $\mathrm{ICH}$, the robustness of an analytical procedure describes to its capability to remain unaffected by small and deliberate variations in method parameters. Robustness was performed by small variation in the chromatographic conditions and found to be unaffected by small variations such as $\pm 2 \%$ variation in volume of mobile phase composition, $\pm 0.1 \mathrm{ml} / \mathrm{min}$ variation in flow rate of mobile phase, and \pm 0.1 variation in $\mathrm{pH}$.

\section{Specificity}

The specificity of the HPLC method was ascertained by analyzing standard drug and sample solutions. The retention time of AD, RV, and VAL was confirmed by comparing the retention time with that of the standard.

\section{CONCLUSIONS}

A simple isocratic RP-HPLC method with UV detection has been developed for simultaneous determination of $\mathrm{AD}$ and VAL, and RV and VAL. The method was validated for accuracy, precision, specificity, and linearity. The run time is relatively short ( $8 \mathrm{~min}$ ), which enables 
rapid quantification of many samples in routine and quality control analysis of tablets. The method also uses a solvent system with the same composition as the mobile phase for dissolving and extracting drugs from the matrices, thus minimizing noise. Thus, the proposed method is rapid, selective, requires a simple sample preparation procedure, Moreover, the lower solvent consumption leads to a costeffective and represents a good procedure of AD and VAL, and RV and VAL determination in bulk and pharmaceutical dosage forms.

\section{ACKNOWLEDGMENTS}

The authors are thankful to Dr. P. Y. Pawar, Principal, Dr. VVPF'S College of Pharmacy, Vilad, and Ahmadnagar, for providing the necessary facilities to carry out the research work and also thankful to Cure Pharma, Pune, for supplying the gift samples of AD and RV, FDC Ltd., Mumbai, for supplying the gift samples of VAL.

\section{AUTHORS' CONTRIBUTIONS}

Both the authors have contributed equally.

\section{CONFLICTS OF INTEREST}

The authors declared that they have no conflicts of interest.

\section{REFERENCES}

1. Beale JM Jr., Block JH. Wilson and Gisvold's Textbook of Organic Medicinal and Pharmaceutical Chemistry. $12^{\text {th }}$ ed. New Delhi: Wolters Kluwer (India) Pvt., Ltd.; 2011. p. 614-54.

2. Lemke TL, Williams DA, Roche VF, William Zito S. Foyes Principles of Medicinal Chemistry. $7^{\text {th }}$ ed. New Delhi: Wolters Kluwer (India) Pvt., Ltd.; 2013, p. 762-826.

3. The Royal Society of Chemistry. The Merck Index, An Encyclopaedia of Chemicals, Drugs and Biological. $15^{\text {th }}$ ed. Cambridge UK: The Royal Society of Chemistry; 2013. p. 87, 1840, 1540 .

4. Allen LV Jr., editor. Remington, the Science and Practice of Pharmacy. $22^{\text {nd }}$ ed., Vol. 1. London: Pharmaceutical Press; 2013. p. 1322.

5. Brayfield A. Martindale (The Complete Drug Reference). $38^{\text {th }}$ ed. London: Pharmaceutical Press; 2014(A). p. 632.

6. Hemke A, Bhure M, Anjankar V, Gupta K. Validated RP-HPLC method for simultaneous determination of amlodipine, hydrochlorothiazide and valsartan in pharmaceutical formulation. Int J Pharm Technol 2013;5: 5383-92.

7. Kavathia A, Misra M. Development and validation of RPHPLC and UV spectrophotometric method for rapid simultaneous estimation of amlodipine and benzepril in pure and fixed dose combination. Arab J Chem 2017;10 Supp 2:3021-8.

8. Modi JG, Patel JK. Stability indicating RP HPLC method for the simultaneous determination of amlodipine besylate and azilsartan medoxomil in tablet dosage form. Indian Drugs 2016;53:51-61.

9. Chhalotiya VK, Sindhav JR, Shah DA, Mehta FA, Bhat KK. Simultaneous estimation of moxonidine and amlodipine besylate in their pharmaceutical dosage form by stability indicating LC method. Indian Drugs 2016;53:24-31.

10. Solanki TB, Shah PA, Patel KG. Central composite design for validation of HPLC method for simultaneous estimation of olmesartan, medoxomil, amlodipine besylate and hydrochlorothiazide in tablets. Indian J Pharm Sci 2014;76:179-87.

11. Wankhede SB, Raka KC, Wadkar SB, Chitlange SS. Spectrophotometric and HPLC methods for simultaneous estimation of amlodipine besilate, losartan potassium and hydrochlorothiazide in tablets. Indian J Pharm Sci 2010;72:136-40.

12. EI-Gizaway SM, Abdelmageed OH, Omar MA, Deryea SM, Abdel-Megied AM. Development and validation of HPLC method for simultaneous determination of amlodipine, valsartan, hydrochlorothiazide in dosage form and spiked human plasma. Am J Anal Chem 2012;3:422-30.

13. Talele GS, Porwal PK. Development of validated bioanalytical HPLCUV method for simultaneous estimation of amlodipine and atorvastatin in rat plasma. Indian J Pharm Sci 2015;77:742-50.

14. Jain PS, Patel MK, Bari SB, Surana SJ. Development and validation of HPTLC method for simultaneous determination of amlodipine besylate and metoprolol succinate in bulk and tablets. Indian J Pharm Sci 2012;74:152-6.

15. Pandya J, Sanyal M, Pranav S. Simultaneous densitometric analysis of amlodipine, hydrochlorothiazide, lisinopril and valsartan by HPTLC in pharmaceutical formulations and human plasma. J Liq Chromatogr Related Technol 2017;40:467-78

16. Vojta J, Jedlička A, Coufal P, Janečková L. A new, rapid, stabilityindicating UPLC method for separation and determination of impurities in amlodipine besylate, valsartan and hydrochlorothiazide in their combined tablet dosage form. J Pharm Biomed Anal 2015;109:36-44.

17. Ghule AS, Thomas T, Joseph M, Navyasree KS, Bhat K. Simultaneous estimation of telmisartan, hydrochlorothiazide and amlodipine besylate in tablet preparation by chemo metric assisted spectrophotometric analysis. Indian Drugs 2018;55:59-66.

18. Usharani N, Divya K, Ashrtiha VV. Development and validation of UV derivative spectroscopic method for the determination of amlodipine besylate and valsartan in tablet dosage form and comparison of the developed methods by students' test. Indian J Pharm Educ Res 2017;57: 776-82.

19. Saminathan J, Vetrichelvan T. UV spectrophotometric correction method for simultaneous estimation olmesartan, medoxomil, amlodipine besylate and hydrochlorothiazide in combined tablet dosage form. Indian Drugs 2017;54:33-8.

20. Patel MP, Patel MR, Hasumati R, Noolvi MN, Shah N. Simultaneous estimation amlodipine besylate and indapamide by dual wavelength spectrophotometric method for the combined pharmaceutical dosage form. Indian Drugs 2014;51:50-4.

21. Galande VR, Baheti KG, Indraksha S, Dehghan MH. Estimation of amlodipine besylate, valsartan and hydrochlorothiazide in bulk mixture and tablet by UV spectrophotometry. Indian J Pharm Sci 2012;74:18-23.

22. Al-Tamimi DJ, Maraie NK, Arafat T. Comparative bioavailability (bioequivalence) study for fixed dose combination tablet containing amlodipine, valsartan and hydrochlorothiazide using a newly developed HPLC-MS/MS method. Int J Pharm Pharm Sci 2016;8:296-305.

23. Sharma T, Si S. A validated gradient stability indicating LC method for the analysis of valsartan in pharmaceutical dosage form. Int J Pharm Pharm Sci 2016;8:128-33

24. Kalyani R, Rao AL. Analytical method development and validation of alisikiren and valsartan in bulk and tablet dosage form by RP HPLC. Indian Drugs 2015;52:5-9.

25. Bianchini RM, Castellano PM, Kaufman TS. Characterization of two new potential impurities of valsartan obtained under photodegradation stress condition. J Pharm Biomed Anal 2011;56:16-22.

26. Virani P, Sojitra R, Raj H, Jain V. Chromatographic method for irbesartan and its combination with other drugs. J Crit Rev 2015;2:7-11.

27. Sreenivasa Reddy M, Kumar L, Attari Z, Verma R. Statistical optimization of extraction process for the quantification of valsartan in rabbit plasma by a HPLC method. Indian J Pharm Sci 2017;79:16-28.

28. del Rosario Brunetto M, Contreras Y, Clavijo S, Torres D, Delgado Y, Ovalles F, et al. Determination of losartan, telmisartan, and valsartan by direct injection of human urine into a column-switching liquid chromatographic system with fluorescence detection. J Pharm Biomed Anal 2009;50:194-9.

29. Krishnaiah Ch, Reddy AR, Kumar R, Mukkanti K. Stability-indicating UPLC method for determination of valsartan and their degradation products in active pharmaceutical ingredient and pharmaceutical dosage forms. J Pharm Biomed Anal 2010;53:483-9.

30. Ibrahim M. Investigation on thermal stability and purity determination of two antihypertensive drugs, valsartan and losartan potassium. Int J Curr Pharm Res 2015;7:64-9.

31. Kaila HO, Ambasana MA, Thakkar RS, Saravaia HT, Shah AK. A new improved RP HPLC method for assay of rosuvastatin calcium in tablet. Indian J Pharm Sci 2010;72:592-8.

32. Beludari MI, Prakash KV, Mohan GK. RPHPLC method for simultaneous estimation of rosuvastatin and ezetimibe from their combination dosage form. Int J Chem Anal Sci 2013;4:205-9.

33. Swathi Sri D, Hemant Kumar T, Vara Prasadarao K, Srinivasa Rao Y. Validated RP-HPLC method for simultaneous determination of rosuvastatin calcium and ezetimibe in pharmaceutical dosage form. Int J Pharm Pharm Sci 2015;7:209-13.

34. Shah A, Patel CN, Shah NJ. UV spectrophotometric method for simultaneous estimation of Rosuvastatin calcium and hydrochlorothiazide in their combined dosage forms. Indian Drugs 2018;55:63-6.

35. Singh R, Khan T. Analytical method development and validation studies for the estimation of aspirin, clopidogrel bisulphate and rosuvastatin calcium in fixed dose combination by UV spectroscopy. Indian Drugs 2017;54:43-7.

36. Kumar TR, Shitut NR, Kumar PK, Vinu MC, Kumar VV, Mullangi R, et al. Determination of rosuvastatin in rat plasma by HPLC: Validation and its application to pharmacokinetic studies. Biomed Chromatogr 
2006;20:881-7.

37. Yulianita R, Sopyan I, Muchtaridi M. Forced degradation study of statins: A review. Int J Appl Pharm 2018;10:38-42.

38. British Pharmacopoeia. Medicines and Healthcare Products Regulatory Agency London: British Pharmacopoeia; 2015. p. I-153, II-1144.

39. Indian Pharmacopoeia, Government of India, Ministry of Health and Family Welfare. The Indian Pharmacopoeia Commission. $7^{\text {th }}$ ed., Vol. 2 ,
3. Ghaziabad: Indian Pharmacopoeia; 2014. p. 1045, 2684, 2951.

40. International Conference on Harmonization (ICH). Q2A: Text on Validation of Analytical Procedures: Definitions and Terminology. Vol. 60. US FDA Federal Register; 1995.

41. International Conference on Harmonization (ICH). Q2B: Validation of Analytical Procedures: Methodology. Vol. 62. US FDA Federal Register; 1997. 